\title{
El Abencerraje: una lección de virtud en los albores del confesionalismo filipino*
}

\author{
The Abencerrage: A lesson of virtue \\ at the beginning of the Philip the II's confessionalism
}

\author{
Eduardo Torres Corominas \\ Universidad Complutense de Madrid
}

\section{RESUMEN}

Entre 1561 y 1565 , vieron la luz las tres versiones de El Abencerraje hoy conocidas - Crónica, Diana e Inventario - cuya lección moral, basada en los principios del mejor humanismo, contrastaba con el incipiente proceso de confesionalización emprendido por la Monarquía hispana en esas mismas fechas. A partir de la reconstrucción de aquellos tres contextos de escritura $-\mathrm{y}$ encuadrando faccionalmente a los sucesivos refundidores de la pieza: el servidor de Jiménez de Embún, Jorge de Montemayor y Antonio de Villegas- el presente trabajo trata de demostrar, desde los estudios sobre la Corte en España, cómo la primera novela morisca de nuestras letras constituyó, en tanto que discurso ideológico, un ataque frontal contra el confesionalismo filipino surgido desde la filas de la oposición política.

Palabras Clave: Abencerraje, novela morisca, confesionalismo, Embún, Montemayor, Villegas, corte.

\begin{abstract}
Between 1561 and 1565 the three known versions of El Abencerrage -Crónica, Diana and Inventario - were printed. The moral lesson of these works, based on the principles of the humanism, is opposite to the process of confessionalization promoted by the Hispanic Monarchy in those dates. From the reconstruction of those three writing contexts - and knowing the courtesan faction to which the successive adapters of the work belonged: Jiménez de Embún's servant, Jorge de Montemayor and Antonio de Villegas - this work attempts to prove, from the studies on the Spanish Court, how the first Spanish Moorish novel was, understood as an ideological discourse, a frontal attack against Philip the II's confessionalism arised from the political opposition.
\end{abstract} Court.

Key words: Abencerrage, Moorish novel, Confessionalism, Embún, Montemayor, Villegas,

* Este trabajo ha sido realizado dentro de los proyectos de investigación: «Creación y desarrollo de una plataforma multimedia para la investigación en Cervantes y su época», concedido por el Ministerio de Ciencia e Innovación, con referencia: FFI2009-11483; y «Las contradicciones de la Monarquía Católica: la Corte de Felipe IV (1621-1665)», también del Ministerio de Ciencia e Innovación, con referencia: HAR2009-12614-C04-01. 
La riqueza semántica de $\mathrm{El}$ Abencerraje, considerada tradicionalmente como la primera novela morisca de la literatura española, ha permitido elaborar, a lo largo del tiempo, numerosas interpretaciones de la misma en las que se ha tratado de vincular — de un modo u otro- el sentido de la obra con el contexto histórico y cultural que la vio nacer. Si desde el punto de vista literario, a pesar de su carácter fundacional, se ha destacado su dependencia con respecto a la historiografía medieval, el pensamiento neoestoico o las tradiciones caballeresca y sentimental — de las que toma elementos diversos para constituir una pieza de nuevo cuño-, desde una perspectiva histórica, la crítica ha subrayado, por encima de todo, la relación que parece vislumbrarse entre la ejemplaridad del relato -inspirado en valores como la tolerancia o la amistad, propios del mejor humanismo - y la particular encrucijada histórica a la que se enfrentaron, a mediados del siglo XVI, las minorías de moriscos y judeoconversos españoles. Así, personajes como Jerónimo Jiménez de Embún o Jorge de Montemayor, implicados directamente en la génesis de la novela, han dado pie al desarrollo de esta línea interpretativa que, a grandes rasgos, considera a El Abencerraje como un producto ideológico contrario a ese lento pero inexorable proceso que condujo, al menos desde 1530, al cierre de la Monarquía hispana tanto en el plano político — con la creciente preeminencia de las facciones cortesanas más intransigentes - y social —con la generalización de los estatutos de limpieza de sangre-, como en el ámbito religioso - con la asunción y defensa, por parte de la Corona, de un catolicismo hispano definido por contraste frente al protestantismo-y cultural, con el desarrollo de nuevos y más estrictos mecanismos de control sobre la actividad intelectual. Significativamente, dicho proceso culminaría, tras la convulsa regencia de doña Juana de Austria — durante la que se aprobó la pragmática sobre la impresión de libros (1558), se redactó el famoso Índice de Valdés (1559) y se reprimieron severamente los focos de luteranismo descubiertos en Andalucía y Castilla (1558-1559)—, en fechas muy próximas a la publicación de las tres versiones de El Abencerraje (1561-1565), cuando Felipe II, desengañado ante el fracaso de las medidas conciliadoras adoptadas durante sus primeros años de reinado (1559-1565), decidió aplicar, mediada la década de 1560, una vigorosa política orientada a consumar la centralización institucional de la Monarquía y la implantación, entre los súbditos del Imperio, de un riguroso sistema de ideas y creencias cimentado en los principios del confesionalismo católico ${ }^{1}$.

Tomando como punto de partida estas lecturas - cuyas conclusiones, en líneas generales, compartimos-, es nuestra intención ofrecer en el presente trabajo una novedosa visión de El Abencerraje sustentada en los últimos estudios sobre la Corte en España, los cuales permiten no sólo filiar faccional-

\footnotetext{
${ }^{1}$ Para el conocimiento de aquel proceso, empleamos como instrumento fundamental las siguientes obras de conjunto: Martínez Millán, 1998 y 2000.
} 
mente a los distintos personajes implicados en la génesis del relato —una filiación faccional que lleva aparejada la filiación ideológica de los individuos-, sino disponer también de un panorama claro y nítido de los procesos históricos de fondo elaborado a partir de un exhaustivo análisis empírico —una historia con nombres y apellidos - cuya utilidad para los estudios literarios apenas comenzamos a descubrir. En las páginas que siguen, por consiguiente, repasaremos brevemente la biografía de quienes, como Jerónimo Jiménez de Embún, Jorge de Montemayor o Antonio de Villegas, participaron en la creación y difusión de los tres Abencerrajes con el fin de situarlos en las distintas redes clientelares que, durante el período de transición entre los reinados de Carlos V y Felipe II, pugnaron - también en el plano de las ideas- por hacerse con el control de la Monarquía. A partir de dicho análisis propondremos, en última instancia, una interpretación de la obra donde quede de manifiesto la relación de su sentido tanto con el entorno cortesano del que surgió - y desde el que se proyectó a la España de su tiempo- como con aquellas corrientes de pensamiento que, tras haber arraigado en época pretérita entre los sectores más intransigentes, lograron erigirse por aquellos días en ideología oficial de la Corona, desplazando a otras posibles vías - herederas de una tradición cultural y espiritual genéticamente opuesta al confesionalismohacia los límites de la heterodoxia, esto es, hacia las fronteras del edificio político y social construido por la Monarquía hispana de Felipe II.

La cuestión, por tanto, tal y como ha sido planteada, nos obliga a volver la mirada hacia los diversos contextos de escritura de los que surgieron las tres versiones hoy conocidas de El Abencerraje; aquéllas que, bien en solitario, bien en compañía de otros textos, circularon a comienzos de la década de 1560 por el territorio de Castilla, sin que todavía haya podido resolverse definitivamente el enigma de su relación y primogenitura. Aunque ya hemos expuesto en otro lugar nuestra opinión sobre el particular ${ }^{2}$, es preciso recordar cuando menos los datos esenciales del problema: de El Abencerraje se conocen tres versiones —Crónica (1561), Diana (1562) e Inventario (1565)_ aparecidas en varias ediciones impresas, muy próximas entre sí, que responden a un ideal literario diferente en cada caso. Es decir, son textos que, a partir de un tronco argumental común, sufrieron un proceso de reelaboración por el que la obra fue modificada de forma muy acusada - conforme al usus scribendi de cada mano - tanto en su estructura interna, como en el tratamiento de los motivos, la disposición sintáctica de los párrafos y el léxico. No nos enfrentamos, por consiguiente, a un único Abencerraje, sino a tres formas de la novela surgidas como consecuencia de distintos trabajos de refundición que, aunque no alteraron en lo fundamental el sentido del relato, sirvieron para adaptarlo —en cada caso- a un determinado ideal estético y filosófico.

La llamada versión Crónica — la más antigua de cuantas conocemos- se

\footnotetext{
${ }^{2}$ Nuestra hipótesis quedó recogida por extenso en Torres Corominas, 2008a: 294-321.
} 
ha recuperado a partir de dos ediciones impresas que se conservan incompletas pero que, unidas, resultan complementarias, de modo que permiten reconstruir la novela de principio a fin. La primera, denominada Chrónica ${ }^{3}$, se acabó de imprimir, según el colofón, en casa de Miguel Ferrer, en Toledo, el 12 de octubre de 1561. Es un pequeño libro en octavo al que tan sólo le falta el folio inicial del pliego $\mathrm{A}$ - en el que tendría cabida la portada y el comienzo de la dedicatoria- y que, probablemente, carecía de preliminares. Por fortuna, es posible reconstruir aquel fragmento acudiendo al segundo miembro de la familia, la llamada Corónica ${ }^{4}$, cuyas primeras páginas se conservan íntegramente. Muy semejante en su materialidad a la anterior, esta Parte de la Corónica el ínclito infante don Fernando que ganó a Antequera - tal y como reza el título de la portada- se adaptó igualmente al estrecho molde del octavo en una edición que, por desgracia, no informa acerca de la fecha y el lugar donde vio la luz. Su texto, en fin, todavía más breve que el de la Chrónica toledana, queda truncado a mitad del relato, concretamente, en el momento de la separación de Abindarráez y Narváez, una vez concluida la confesión autobiográfica del moro.

Tras estas ediciones -y siempre en el orden cronológico señalado por los impresos - apareció, interpolada al final del libro cuarto de la Diana de Jorge de Montemayor, la segunda versión de El Abencerraje ${ }^{5}$, que se ofreció por vez primera a los lectores en la edición vallisoletana preparada en casa de Francisco Fernández de Córdoba. Como informa el colofón, las tareas de impresión concluyeron el 7 de enero de 1562, si bien en los preliminares figura el 10 de octubre de 1561 como fecha de la licencia. A finales de aquel otoño, pues, pasó a letras de molde este Abencerraje pastoril, la versión Diana, que saldría a la calle sólo a comienzos del año siguiente. En este caso, El Abencerraje constituía, como las diversas composiciones poéticas añadidas al final del volumen ${ }^{6}$, una sabrosa novedad editorial que, sin duda, sirvió para incrementar, tras dos o tres años de exitosa circulación impresa, el atractivo comercial de la Diana. A partir de entonces y durante un largo período, la primera novela pastoril de nuestras letras no volvería a estamparse sin su correspondiente Abencerraje, de modo que, al calor de esta feliz alianza editorial, la versión Diana alcanzó fama y celebridad universal, siendo la que mayoritariamente leyeron los contemporáneos.

Finalmente, tres años y medio más tarde, en la noble villa de Medina del Campo, salió de las prensas de Francisco del Canto la edición príncipe del

${ }^{3}$ La Chrónica de Toledo puede leerse en López Estrada, 1959.

${ }^{4}$ La Corónica se recoge en López Estrada, 1957: 346-373.

${ }^{5}$ La versión interpolada en la Diana de Montemayor fue editada por Fosalba Vela, 1990.

${ }^{6}$ A partir de la edición zaragozana de Pedro Bernuz, 1560, se observan distintos procedimientos editoriales destinados a incrementar el atractivo comercial de la Diana, como la reducción de formato y la paulatina adición de nuevas composiciones al final del volumen. Así se colige de la secuencia presentada por Fosalba Vela, 1994: 93 y ss. 
Inventario de Antonio de Villegas, un cancionero particular de sabor misceláneo ${ }^{7}$ donde —a la altura de 1565 y tras no haber hecho uso de un antiguo privilegio obtenido en 1551 - el poeta medinense reunió para la imprenta prosas y versos elaborados a lo largo de más de veinte años de escritura. Al final de aquel volumen, casi a modo de apéndice, incluyó entre sus obras un tercer Abencerraje, la versión Inventario, que se separaba en no pocos pasajes de los dos anteriores. Esta tercera forma de la novela, por tanto, recorrió los caminos del reino inserta en el poemario de Villegas cuando Crónica y Diana llevaban ya varios años circulando y eran textos bien conocidos. La corta trayectoria del Inventario, sin embargo, impidió que este postrer Abencerraje alcanzase en su tiempo mayor gloria literaria ${ }^{8}$; de manera que, tras ser condenado al ostracismo durante un largo período, sólo en época reciente ha sido recuperado y valorado adecuadamente por la crítica? .

Acerca de la relación existente entre las tres versiones, a lo largo de las últimas décadas se han vertido numerosas opiniones sin que ninguna de ellas pueda considerarse definitiva. El problema, en efecto, resulta complejísimo desde un punto de vista formal, de manera que el cotejo de variantes, por sí mismo, antes que aclarar el enigma, lo complica aún más si cabe. En resumen, y tras descartar aquellas hipótesis que postulaban una redacción temprana de la versión Inventario ${ }^{10}$, puede afirmarse que, con los datos de que disponemos, sólo parecen admisibles dos explicaciones, cuyo punto en común es aceptar la primogenitura de la versión Crónica. A partir de aquel estadio, la primera — defendida por Eugenia Fosalba Vela ${ }^{11}$ tras realizar un exhaustivo análisis comparativo de los textos- postula la existencia de un antepasado común (hoy perdido) a Diana e Inventario (una especie de Crónica ligeramen-

\footnotetext{
${ }^{7}$ Como cancionero particular - y no como miscelánea- debe ser considerado el Inventario de Villegas debido tanto a la naturaleza de sus materiales como a la génesis editorial del volumen. Al respecto, véase Montero Delgado, 2004.

${ }^{8}$ El Inventario de Antonio de Villegas sólo disfrutó de dos ediciones impresas (1565 y 1577), ambas en vida del autor, antes de caer en el olvido. Una vez reconocidas las virtudes estéticas de su Abencerraje, la obra cobraría nueva vigencia para los estudios filológicos. Fruto de este interés nacieron sus dos ediciones modernas: Villegas, 1955-1956; y la contenida en Torres Corominas, 2008a: 469-729.

${ }^{9}$ Como consecuencia de dicho reconocimiento, su texto sirve de base a la edición de referencia de la obra, al cuidado de F. López Estrada: El Abencerraje. Novela y romancero, 1993.

${ }^{10}$ Nos referimos a las hipótesis expuestas en López Estrada, 1957: 15-65, y 1959: 32 46; y Bataillon, 1964, donde el Abencerraje de Villegas era situado en un lugar preeminente del stemma debido tanto a su calidad literaria como a su posible redacción temprana. Todas ellas han quedado desvirtuadas tras el hallazgo del memorial de la Cámara de Castilla donde Villegas, a comienzos de 1551, describía su cancionero, entre cuyos materiales no se hallaba El Abencerraje (cfr. Torres Corominas, 2005).

${ }^{11}$ Fosalba Vela abordó por vez primera la cuestión en 1990: 34-105; si bien sus últimas opiniones sobre el particular quedan recogidas en 1994: 137-184.
} 
te mejorada) al que deberían atribuirse las lecciones comunes de ambos textos frente al primero. Dicho testimonio habría sido empleado en distinto momento como fuente por Montemayor y Villegas a la hora de redactar sus respectivos Abencerrajes. La segunda hipótesis vigente —que, en líneas generales, hacemos nuestra - fue planteada hace tiempo por Keith Whinnom ${ }^{12}$, quien, respetando el orden establecido por las fechas de impresión - y dando por hecho el carácter plagiario de Diana e Inventario- consideró la posterioridad de éste último, para cuya redacción Antonio de Villegas se habría servido, a discreción, de las versiones Crónica y Diana. De este modo se explicaría el caso de contaminación que se observa en el cotejo.

Sin entrar en mayores disquisiciones, nos limitaremos a esbozar en las líneas que siguen nuestra reconstrucción de los hechos, en la que se intentan integrar y armonizar las conclusiones del análisis formal con otras noticias y argumentos extraídos del contexto editorial en que surgieron los diversos textos, del ideal estético e ideológico que inspiró el usus scribendi de cada uno $\mathrm{y}$, finalmente, de la trayectoria vital y literaria de los distintos personajes que se emplearon en la refundición de la obra.

Así las cosas, todo parece indicar que la historia de la novela se inició en tierras aragonesas, concretamente, a orillas del Jalón, en la pequeña corte señorial de Jerónimo Jiménez de Embún, señor de Bárboles y Huirita, lugar donde servía — según él mismo declara en la dedicatoria - el autor de la versión Crónica, primera forma de la novela. Si damos crédito a sus palabras, a partir del hallazgo de un viejo manuscristo, una «parte de corónica» que «andava oculta y estava inculta» concibió la idea de restaurar y reescribir la obra para honrar con ella a su señor — «procuré con fin de dirigirla a vuestra merced, lo menos mal que pude, sacarla a luz enmendando algunos defectos della»- de manera que, en rigor, a su mano debería atribuirse sólo la corrección, que no la creación original, de un texto esencialmente ajeno. Saber hasta qué punto intervino en el proceso de escritura es hoy tarea poco menos que imposible al desconocerse a ciencia cierta cuál fuera su fuente ${ }^{13}$. En todo caso, a partir de este estadio — gracias a la difusión impresa — habría quedado ya fijado en lo fundamental el texto de lo que hoy conocemos como El Abencerraje, hecho absolutamente decisivo si se considera que, hasta ese momento, aquella anécdota germinal citada en la dedicatoria - ese breve relato de frontera, esa «parte de corónica»— había vivido, como la literatura tradicional anónima, «en variantes», sometida a las vicisitudes de la transmisión manuscrita. De este modo, como en el caso de muchos romances del siglo XVI o de la narrativa caballeresca breve, en la génesis de El Abencerraje se hallaría

\footnotetext{
12 Véase Whinnom, 1959.

${ }^{13}$ Aquella misteriosa fuente pudo asemejarse a la llamada Historia del moro y Narváez, relato de unas mil palabras ambientado en la frontera granadina que fuera estudiado por Carrasco Urgoiti, 1968.
} 
la recreación de un atractivo episodio historiográfico — extraído de esa inagotable cantera que constituían las crónicas medievales- que, una vez reelaborado, habría disfrutado, tanto en la Crónica del ínclito infante don Fernando, que ganó a Antequera como en las sucesivas versiones del relato, de nueva vida literaria ${ }^{14}$.

Bajo la protección de Jerónimo Jiménez de Embún — cuya encrucijada vital aparece íntimamente ligada a la suerte de las comunidades moriscas arraigadas en sus posesiones patrimoniales - se configuró, por tanto, este primer Abencerraje, que, a pesar de los esfuerzos de su refundidor, conservó todavía muchos de los defectos achacados a su fuente. La Crónica, en efecto, a pesar de intentar aderezar el episodio con elementos tomados de la historiografía medieval, el universo caballeresco o el romancero, no alcanzó a pulir debidamente la pieza, que conservó una sintaxis farragosa, un léxico poco acertado y un inadecuado tratamiento de los motivos, cuyo desarrollo - como el profuso intercambio de regalos que, al final de la obra, entorpece el curso de su enseñanza - se ajustaba mal, generalmente por exceso, al sentido moral que la anécdota primigenia encerraba. Sea como fuere, lo cierto es que la Crónica del ínclito infante don Fernando - tras ser compuesta en un momento indeterminado de la década de $1550^{15}$ — pasó a letras de molde en diversas ediciones impresas que, como la Corónica, aparentaban ser, a primera vista, pequeños libros de caballerías ${ }^{16}$. Al amparo de la buena fortuna editorial del género al que externamente se adscribía, la versión Crónica disfrutó al menos de dos ediciones - aunque probablemente existieran otras, alguna de ellas más temprana- que, como tarde en 1561, dieron a conocer el relato en Castilla y, muy probablemente, también en su Aragón natal. Por medio de estos librillos, por consiguiente, la obra se difundió de forma anónima, sin autor conocido ni privilegio real, contraviniendo lo estipulado en la pragmática de 1558. Se convertía así en presa fácil para otros escritores y libreros, que podían emplearla con libertad — tras pulir sus defectos más evidentes y rehacer determinados pasajes - para sazonar otros productos editoriales. Eso fue precisamente lo que ocurrió en las dos versiones que, tras la Crónica, dieron a conocer la historia de Abindarráez y Jarifa.

La primera de ellas, el Abencerraje pastoril incluido a finales de 1561 en la Diana de Montemayor, debió componerse — según nuestra hipótesis— so-

${ }^{14}$ Esta idea subyace bajo muchos de los estudios críticos que han abordado la cuestión textual del Abencerraje, pero quien la expresa con mayor claridad es Carrasco Urgoiti, 2001: 53-55.

15 Véase al respecto Merimée, 1928.

${ }^{16}$ La versión Crónica, en su apariencia externa, guarda significativas semejanzas con los libros de caballerías en tanto que género editorial, tal y como puede comprobarse a través de Lucía Megías, 2000. Estas semejanzas se observan, por ejemplo, en el grabado de la portada (2000: 215-218) o en la presentación de la obra como una supuesta «crónica» (2000: 281). 
lamente a partir de la Crónica ${ }^{17}$, que fue profundamente retocada — depurando errores e impertinencias, intercalando versos, amplificando los motivos amorosos, ahondando en la introspección psicológica de los personajes o reduciendo los pasajes bélicos- para adaptar el cuento al universo bucólico que le daba acogida. Debido a las incuestionables concomitancias estilísticas que esta versión manifiesta con respecto a la Diana, la crítica ha deducido con acierto que difícilmente pudo llevar a cabo la tarea de reescritura otra mano que no fuese la del propio Montemayor ${ }^{18}$. Si aceptamos esta afirmación y consideramos que el escritor lusitano murió prematuramente en el Piamonte en febrero de 1561, habremos de enfrentarnos inmediatamente a nuevas incógnitas, pues, ¿qué edición manejó Montemayor si tanto Chrónica como Corónica fueron impresas después de su fallecimiento? ${ }^{19}$, ¿cómo pudo llegar a manos de Fernández de Córdoba el manuscrito preparado por el portugués? Para responder al primer interrogante, lo más sencillo resulta postular la existencia de una edición anterior (hoy perdida) de la Crónica, a partir de la que Montemayor habría trabajado, a su regreso de Flandes, entre los años 1559 y 1560, probablemente poco después de haber entregado a las prensas la Diana. Acerca de cómo llegó su Abencerraje al impresor vallisoletano todo es un enigma: quizás el manuscrito quedara en España antes de su partida hacia Italia, quizás alguien lo trajera de allí después de su deceso. En todo caso, con las noticias de que disponemos hoy en día, estamos obligados a concluir que Montemayor, en un momento indeterminado anterior a su muerte, preparó una nueva versión de El Abencerraje con intención de interpolar el relato en el cuerpo de la Diana. Dicha tarea, sin embargo, no pudo concluirla en vida y hubieron de ser otros quienes tomaran el texto preparado por el portugués y

${ }^{17} \mathrm{Si}$ aceptamos la redacción tardía de la versión Inventario (preparada a comienzos de 1565 para incrementar el atractivo del cancionero antes de enviarlo a la imprenta), parece difícil imaginar que, en torno a 1559-1560, circulase ya alguna otra versión de El Abencerraje distinta a la Crónica. En todo caso, la única alternativa posible, una vez descartado el texto de Villegas como fuente para Montemayor, consiste en postular la existencia - como defiende Fosalba Vela - de una cuarta forma de la novela (hoy desconocida) - en términos formales, una Crónica ligeramente mejorada - a partir de la que el lusitano habría emprendido su labor de reescritura. Pero, ¿cuáles fueron las motivaciones que impulsaron la génesis de aquel cuarto texto?, ¿cuál el usus scribendi de su refundidor?, ¿por qué esa nueva versión, siendo manifiestamente superior, no había desterrado todavía a la Crónica entrado el año 1561?, ¿cómo armonizar su hipotética potencia germinal (habría servido de fuente a Diana e Inventario) con una deficiente difusión que, en último extremo, habría provocado la pérdida de todos sus ejemplares? Lo más sencillo es pensar, en conclusión, que sólo la Crónica (en una edición anterior a 1561) pudo estar en manos del portugués mientras adaptaba el relato morisco al universo pastoril de la Diana.

${ }^{18}$ Estas conclusiones se ofrecen en Fosalba Vela, 1994: 66-68. Años atrás, esta misma hipótesis había sido sostenida por Navarro Gómez, 1978.

${ }^{19}$ Podemos confirmar este extremo gracias a la comparación entre Chrónica y Corónica, donde se demuestra la primogenitura de la edición toledana, cuyos trabajos de impresión concluyeron en octubre de 1561. Cfr. López Estrada, 1959: 32-35. 
lo llevaran a la imprenta. El resultado de aquellos trabajos fue la novedosa edición vallisoletana puesta a la venta a comienzos de 1562, cuyo éxito y repercusión han sido ya señalados.

En última instancia, a mediados de 1565, se repitió, en el Inventario de Antonio de Villegas, el mismo procedimiento editorial, al adosarse al cancionero del medinense una tercera versión de El Abencerraje con intención de incrementar sus atractivos comerciales ${ }^{20}$. A partir de Crónica y Diana —que, desde nuestra perspectiva, fueron empleadas con absoluta libertad en el proceso de reescritura- se habría configurado esta postrera forma de la novela, que trató de potenciar en lo posible el sentido moral del relato -eliminando o reduciendo todo aquello que se desviase de este eje, por una parte, y, por otra, introduciendo nuevos elementos que lo apuntalasen, tales como el «cuento de la honra del marido defendida por el amante» o las cartas del final- con intención de ofrecer un «vivo retrato de virtud, liberalidad, esfuerzo, gentileza y lealtad», que es como, literalmente, se define la pieza en su presentación. El hecho de que esta conocida estrategia editorial se materializase ya en la princeps $^{21}$, cuando habitualmente se empleaba para refrescar volúmenes de largo recorrido ${ }^{22}$, quizás pueda explicarse a la luz de ese infructuoso privilegio obtenido en 1551, que ningún librero habría deseado adquirir por falta de confianza en la rentabilidad de los poemas. Andados los años - y modificada notablemente la composición original del Inventario - el poemario contó finalmente con el apoyo de Mateo del Canto, librero de Medina del Campo, quien, para garantizar el éxito de la empresa, habría propuesto o exigido al autor la incorporación de aquel relato que con tanta eficacia contribuía por entonces al triunfo de la Diana.

Sólo en aquella coyuntura es posible trazar la relación entre la novela morisca y un poeta de tono doliente anclado en la poética del amor cortés. Y es que, si en el caso de Montemayor las semejanzas estilísticas permitían sostener la hipótesis de su autoría - a pesar de su temprana muerte-, en el caso de Villegas sucede lo contrario, pues su probada vecindad con respecto

\footnotetext{
${ }^{20}$ La génesis del Inventario impreso en 1565 puede conocerse a través de Torres Corominas, 2008a: 250-293.

${ }^{21}$ En efecto, el análisis de la estructura del Inventario pone de manifiesto que, tras los poemas al modo castellano y los poemas al modo italiano, la canción petrarquista que cerraba esta última sección estaba concebida para clausurar poéticamente el volumen. Que $E l$ Abencerraje se añada, casi a modo de apéndice, detrás de la misma, supone la introducción de un elemento heterogéneo en el corpus del cancionero que resulta un tanto extraña por tratarse de la princeps. Cfr. Torres Corominas, 2008a: 284 y ss.

${ }^{22}$ El propio Inventario se vio sometido a estas estrategias comerciales en su segunda edición (Medina del Campo, 1577) donde se repitieron los mismos procedimientos que en la secuencia de la Diana: reducción del formato $\left(\right.$ de $4^{\circ}$ a $8^{\circ}$ ) y adición de nuevas composiciones al final del volumen, que pasaron a situarse detrás de El Abencerraje rompiendo definitivamente cualquier armonía compositiva. Cfr. Torres Corominas, 2008a: 322-333.
} 
al taller de Francisco del Canto y a la librería regentada por su hermano Mateo, donde se puso a la venta el Inventario mediado el año 1565 - hecho que, sin duda, permitió al autor promover y vigilar personalmente el proyecto editorial- no oculta la distancia existente entre El Abencerraje y el resto del poemario, pues tanto la temática del relato como su cuidado estilo distan notablemente de las inclinaciones - y aun diríamos, de las capacidades literariasmostradas por Villegas en el resto del Inventario. Siendo esto cierto, no lo es menos que, al final de la cadena textual — tal y como defendemos - su labor no habría sido la de creador, sino más bien, como en el caso de los anteriores, la de editor o refundidor de la pieza, y que, situado en aquella privilegiada posición — con Crónica y Diana ante sus ojos- quizás no hubiese necesitado de tanto ingenio para llevar a cabo la tarea. En tales circunstancias, por tanto, ya no resulta tan aventurado postular su participación directa, aunque fuese por encargo del editor, en el proceso de reescritura que dio lugar a la versión Inventario. Es más, se hace difícil imaginar que su cancionero personal —y más si cabe en su edición príncipe- hubiese sido clausurado por un relato totalmente ajeno tanto a su pluma como a sus inclinaciones ideológicas, y que este hecho — que, obviamente, distanciaría a la novela morisca de los demás contenidos - no hubiese sido reseñado de alguna manera, bien en el seno del propio libro, bien a través de alguna referencia externa de la que no tenemos noticia. Por todo ello, lo más coherente es considerar a Antonio de Villegas como el tercer y último refundidor de El Abencerraje, cuya deliciosa anécdota pasó a incrementar, una vez cincelada por el medinense, los alicientes de un poemario necesitado de mayores encantos.

A partir de este esquema, es posible pasar a la reconstrucción de los tres contextos de escritura que dieron lugar, respectivamente, a las tres versiones de $E l$ Abencerraje ya reseñadas, con objeto de dilucidar si, entre el servidor de Jiménez de Embún, Jorge de Montemayor y Antonio de Villegas existió algún vínculo faccional e ideológico que permita aclarar ese sentido crítico de la obra que, a grandes rasgos, ha sugerido ya un importante sector de la crítica. Esta tentativa de aproximación histórica, por tanto, pretende definir con precisión desde qué sectores cortesanos se configuró la novela y contra qué grupos y corrientes se posicionó un relato tan ejemplar e idealista como poco inocente.

En ese sentido, la tradición textual de El Abencerraje nos obliga a volver la mirada, en primer lugar, hacia la corte señorial de Jerónimo Jiménez de Embún, donde, según todos los indicios, tuvo su origen la primera forma de la novela. Sobre el aristócrata aragonés, son clásicos los estudios de $\mathbf{M}^{\mathrm{a}}$. Soledad Carrasco Urgoiti ${ }^{23}$, que tan certeramente describieron la problemática de estos antiguos feudos a mediados del siglo XVI. En aquellos trabajos, Jiménez de Embún quedó encuadrado entre la influyente nobleza aragonesa que, atrincherada tras los fueros del reino y sus propios derechos señoriales, opu-

${ }^{23}$ Nos referimos a Carrasco Urgoiti, 1969 y 1972. 
so, hasta finales de la centuria, una tenaz resistencia contra todo poder externo - bien fuese la Corona, bien fuese la ciudad de Zaragoza - que tratase de interferir en su modo de vida tradicional. En ese sentido - y para la cuestión que nos ocupa - resulta del máximo interés constatar cómo muchos de aquellos señores de vasallos poseían en sus dominios lugares de moriscos, donde los nuevos convertidos practicaban la agricultura sin ser apenas importunados a causa de sus costumbres o creencias. El interés mutuo, por consiguiente, alentaba un clima de tolerancia y permitía la convivencia pacífica entre comunidades separadas desde tiempo inmemorial por la diversidad de sus raíces étnicas, culturales y religiosas.

Para la pervivencia y continuidad de aquel modelo económico y social — reducto del viejo orden feudal heredado de la Edad Media- era preciso, en todo caso, preservar el entorno de injerencias externas, lo que resultaba cada vez más difícil debido a la progresiva expansión del poder real y el consiguiente sistema político de Corte. En efecto, fueron las instituciones centrales de la Monarquía las que, con mayor ahínco, trataron de derribar aquellos muros legales y jurisdiccionales tras los que se parapetaba tanto la nobleza fuerista como la comunidad morisca aragonesa, cuya existencia, mediado el siglo XVI, inquietaba a la Corona por diversas razones. En primer lugar, debido a su deficiente conversión al Cristianismo y su permanencia en el Islam, que constituía un flagrante delito de herejía sobre el que la Inquisición no podía actuar al verse continuamente hostigada en aquel territorio. En segundo término, preocupaba la lealtad de estas comunidades ante un eventual ataque del Turco, que bien podría utilizar a los moriscos como quinta columna para la invasión de la Península. Finalmente, importunaba a la Monarquía el hecho de que, en las zonas dominadas por sus asentamientos, abundase el tráfico de armas y la saca de metales preciosos a Francia, o que los moriscos constituyesen auténticas milicias al servicio de la nobleza y fuesen empleados, por tanto, para repeler cualquier ataque dirigido contra aquellos feudos. Estas eran, pues, las claves del conflicto en el que los moriscos aragoneses se hallaban inmersos a finales de 1558, cuando el Santo Oficio decidió dar un paso adelante.

En efecto, fue en diciembre de ese año cuando la Inquisición promulgó - auspiciada por la Corona, que marchaba ya en pos de la homogeneidad confesional y deseaba, ante todo, recuperar su autoridad sobre Aragón ${ }^{24}$ - un

${ }^{24}$ La prolongada ausencia de Felipe II y el tradicional abandono de Aragón — siempre relegado a un segundo plano en el seno del Imperio Habsburgo- alentaron los desórdenes y rebeliones que culminaron con la revuelta de Zaragoza de 1556. Aquellos hechos motivaron la precipitada huida de Diego Hurtado de Mendoza y de la Cerda, virrey de Aragón (y a la sazón, padre de Ana de Mendoza y suegro de Ruy Gómez de Silva), cuya autoridad se vio menoscabada por quienes esgrimieron contra su soberanía los antiguos fueros del reino. El edicto de desarme (1558) ha de entenderse, por consiguiente, como una de las medidas adoptadas por la Corona para recuperar la autoridad perdida en aquel territorio. Cfr: Rodríguez Salgado, 1992: 429 y ss. 
edicto donde ordenaba el desarme de las comunidades moriscas con el fin de someter aquellos territorios al poder de la Monarquía. De este modo, los nobles vieron gravemente menoscabados tanto sus fueros como sus intereses económicos, por lo que no tardaron en enviar una embajada a Toledo para presentar sus quejas al monarca. Uno de sus emisarios fue Jerónimo Jiménez de Embún, miembro del partido fuerista y firme defensor de las libertades de los moriscos. Éste fue el humus donde nació la primera versión de El Abencerraje, la Crónica, cuya lección de virtud y tolerancia presentaba un modelo de comportamiento que resolvía satisfactoriamente - a través del ejemplo y el convencimiento, no mediante la imposición violenta del vencedor- un conflicto surgido, como en la realidad, entre individuos de distinta ley.

El servidor de Jerónimo Jiménez de Embún que llevó a cabo la redacción del primer Abencerraje, pues, vinculado estrechamente a su señor en el seno de la sociedad cortesana a través de la lógica del servicio-merced ${ }^{25}$, no podía sino compartir el punto de vista de su amo en lo que respecta al problema de la diversidad, cuestión de máxima actualidad a comienzos del reinado de $\mathrm{Fe}$ lipe II. En efecto, al igual que la minoría morisca, la extensa y difusa comunidad judeoconversa - más preparada y competitiva que la anterior - sufría también en el territorio peninsular el repliegue de aquella sociedad que, tras haber agotado otro tipo de procedimientos, buscaba por entonces nuevos mecanismos de exclusión, como los estatutos de limpieza de sangre, para impedir la integración y ascenso de los marranos. En ese sentido, la familia de Jiménez de Embún, comprometida políticamente con la causa morisca, pudo experimentar también en carne propia los rigores del antisemitismo, toda vez que en la genealogía de los señores de Embún había mezcla de sangre judía: recientemente habían emparentado con familias conversas a las que pertenecían, entre otras, la madre y la esposa de don Jerónimo ${ }^{26}$. Por todas estas razones, en consecuencia, es lícito postular que El Abencerraje, surgido en un contexto tan problemático como el descrito, no pudo ser ajeno a estas cuestiones — plenamente vigentes a finales de la década de 1550 - y que, de hecho, sólo al calor de las mismas cobra pleno sentido histórico la labor de reescritura realizada, a orillas del Jalón, por el primer y más genuino autor de la novela.

${ }^{25}$ El criado de Jiménez de Embún concibió la redacción de la Crónica como un acto de servicio hacia su señor, de quien recibiría a cambio, graciosamente, por éste y otros trabajos intelectuales (que podían ir desde la instrucción de los hijos a la preparación de escritos y documentos) las más diversas mercedes. Este modo de relación, que llevaba implícita la comunión ideológica entre los implicados - formaban parte de una misma casa - era propio de la sociedad cortesana y se diferenciaba en no pocos aspectos (era una relación personal, no reglada) de los vínculos profesionales propios del mundo contemporáneo. Así lo explica Álvarez-Ossorio, 1998.

${ }^{26}$ Sobre la genealogía de Jiménez de Embún, son de gran interés los apuntes de Guillén, 1965 (1988): 131-133. 
Cerrado el capítulo aragonés - y una vez proyectado sobre la España de su tiempo a través de las diversas ediciones de la Crónica-El Abencerraje fue recogido y reelaborado por dos escritores de larga trayectoria, Jorge de Montemayor y Antonio de Villegas, que, en distinto momento, se sintieron atraídos por este breve episodio de frontera. Conocer las claves de sus respectivas biografías, prestando especial atención al entorno cortesano en el que se movieron - el círculo cortesano portugués, la facción ebolista ${ }^{27}$ — puede, sin duda, explicar desde un punto de vista ideológico la inclinación que ambos mostraron hacia el relato morisco, donde se ponía en juego, literariamente, un sistema de valores alternativo y opuesto - basado, todavía a mediados del siglo XVI, en los principios del humanismo- a los intransigentes planteamientos del grupo dominante.

Lusitanos eran, en efecto, los orígenes de Jorge de Montemayor ${ }^{28}$, cuya trayectoria cortesana estuvo ligada desde un principio al grupo de servidores hispanoportugueses originariamente constituido en torno al séquito de la emperatriz Isabel, asentado en España desde 1526. Aunque no se conoce con exactitud el momento de su incorporación a la Corte de Carlos V, parece probable que se moviese ya en el entorno de Valladolid a mediados de 1545, cuando la temprana muerte de la princesa María Manuela truncó las expectativas de no pocos servidores lusitanos, que hubieron de regresar a su patria o buscar nuevo acomodo en difíciles circunstancias. Montemayor, como tantos otros miembros del círculo cortesano portugués, lo encontró en la Casa de las Infantas, donde pasó a ejercer como cantor de capilla entrado el año $1547^{29}$. Durante este período escribió su conocido Diálogo espiritual ${ }^{30}$, donde ya se vislumbraba su comunión con la espiritualidad predominante en aquella Casa real.

Superada esta primera etapa a la sombra de las infantas, Montemayor siguió vinculado a la princesa Juana cuando su servicio y el de María se separaron. Entre 1549 y 1552, por consiguiente, el músico portugués permaneció en Castilla junto a su señora ejerciendo ininterrumpidamente como cantor contrabajo. Aquellos años resultarían decisivos para la formación religiosa de doña Juana y sus servidores, pues fue entonces cuando se intensificó sobre todos ellos la influencia del recogimiento — corriente espiritual derivada de la observancia y antecedente directo de la mística- que, desde una fe viven-

${ }^{27}$ Para el conocimiento del origen, composición, ideología y espiritualidad de la facción ebolista, es fundamental el trabajo de Martínez Millán, 1992.

${ }^{28} \mathrm{La}$ trayectoria cortesana de Montemayor ha quedado reconstruida en Torres Corominas, 2012.

${ }^{29}$ Un estudio particular sobre la Casa de las Infantas se ofrece en Ezquerra Revilla, 2000. El momento preciso en que Montemayor ingresó en la misma fue deducido con acierto por Ruiz Cabello, 2000: 134, n. 21.

${ }^{30} \mathrm{Al}$ respecto, véase el estudio y la edición contenidos en Montemayor, 1998; así como los comentarios de Esteva de Llobet, 2009: 90-126. 
cial, trataba de acceder a Dios a través del amor y la experiencia afectiva. De esta espiritualidad bebieron Ignacio de Loyola y muchos jesuitas de los primeros tiempos, cuya predicación caló hondamente entre las infantas y algunos servidores de su Casa ${ }^{31}$, como Leonor de Mascareñas o Beatriz de Melo, quienes, a su vez, contribuyeron a consolidar esta tendencia entre el grupo de cortesanos hispanoportugués que compartía ya unos mismos intereses de grupo y una determinada ideología política.

Totalmente integrado en aquellas redes clientelares en torno a las que se iba organizando una verdadera oposición política a la facción dominante — donde ya despuntaba la figura de Fernando de Valdés-, Montemayor prosiguió su andadura cortesana, que lo devolvió a Portugal a finales de 1552, cuando acompañó a la princesa Juana hacia sus desposorios. En la Corte de Lisboa debió vivir prósperamente — tal y como se deduce de unos versos de Sá de Miranda- ejerciendo el oficio de aposentador real (y sin perder, probablemente, el de cantor de capilla) hasta que la desgraciada muerte del príncipe Juan, el 2 de enero de 1554, desvió nuevamente su camino. Por aquellos días, verían la luz — primero en Medina del Campo (1552 o 1553) y después en Amberes (1554) ${ }^{32}$ - las Obras de Montemayor, un variado cancionero dedicado a sus señores, los príncipes de Portugal, donde se reunían versos devotos y profanos elaborados a lo largo de su juventud.

A mediados de $1554-y$ siguiendo una cierta lógica cortesana- Montemayor debió regresar a España para instalarse en la Corte de Valladolid junto a doña Juana durante la primera etapa de su regencia. Allí frecuentaría su círculo más íntimo, al que pertenecían los duques de Valencia de don Juan, y allí tendría tiempo de confeccionar — añadiendo, desechando y reordenando materiales - los dos nuevos volúmenes poéticos que serían estampados poco tiempo después en los Países Bajos. Precisamente, en la dedicatoria de su Segundo cancionero espiritual (Amberes, 1558), dirigida a don Jerónimo de Salamanca, se halla la prueba fehaciente de su presencia en Castilla, pues en ella Montemayor revela que sólo se atrevió a publicar aquellos versos de devoción «después de haber trabajado [...] muchos días en este libro, y comunicado lo que en él hay con muchos teólogos, así en estos estados de Flandes como en España, especialmente en el Colegio de San Gregorio de Valladolid...» $»^{33}$.

Parece evidente, por tanto, que el portugués no permaneció en la Península hasta el final de la regencia, pues, al calor de la decisiva guerra que se libraba entonces contra Francia, pasó a Flandes antes de 1557 en busca de

\footnotetext{
${ }^{31}$ Sobre la ideología y espiritualidad predominantes entre los servidores de doña Juana de Austria ha trabajado Martínez Millán, 2003.

${ }^{32}$ La historia editorial de las Obras de Montemayor fue reconstruida recientemente por Moll, 2008.

${ }^{33}$ Véase Montemayor, 2006: 164.
} 
mejor fortuna, tal y como confirman sus poemas titulados Yéndose el autor a Flandes y Partiéndose para la guerra. En los Países Bajos combatiría como soldado de los ejércitos imperiales con el fin de obtener el favor real y medrar en la Corte. A pesar de sus esfuerzos, sin embargo, no encontró allí adecuada recompensa, pues en su Epístola a un grande de España sobre los trabajos de los reyes, escrita en Amberes a comienzos de 1558, muestra abiertamente su desengaño cortesano al verse olvidado y mal pagado por la Corona tras más de diez años de servicio ${ }^{34}$. En la misma línea debe interpretarse la Epístola a Ramírez Pagán, donde la alabanza de la vida pastoril es introducida por un inequívoco y revelador menosprecio de $\operatorname{Corte}^{35}$. Su presencia en Flandes, en todo caso, explicaría el surgimiento de dos nuevos volúmenes impresos: el Segundo cancionero (con sus obras de amores) y el Segundo cancionero espiritual (con sus obras de devoción) ${ }^{36}$. En éstas últimas, el portugués tomaba una vez más la peligrosa senda - siempre en los límites de la heterodoxia - de aquellos espirituales y recogidos que tanta influencia ejercieran en el entorno más íntimo de la princesa Juana ${ }^{37}$.

Por tal motivo $-\mathrm{y}$ a pesar de las consultas realizadas por Montemayor a los teólogos del Colegio de San Gregorio antes de entregar a la imprenta el Segundo Cancionero espiritual - éste, junto con todas sus obras de devoción, pasó a engrosar la lista de textos condenados en el Catálogo de libros prohibidos de 1559, donde todo indicio de iluminismo fue severamente castigado. Melchor Cano y los demás censores, por consiguiente, no pasaron por alto en aquel riguroso escrutinio ni su espiritualidad recogida, ni su insistencia en los beneficios de Cristo, ni su exaltación de la fe, ni sus inclinaciones místiconaturalistas, ni su proximidad doctrinal a figuras como Raimundo de Sabunde, Girolamo Savonarola, Erasmo de Rótterdam o Bartolomé de Carranza ${ }^{38}$, ni tampoco — por qué no decirlo — su filiación ebolista, que lo convertía en enemigo político de quienes promovían desde Valladolid la imposición de la intransigencia religiosa en España. Quizás por miedo a la Inquisición, precisamente, Montemayor, a su regreso de Flandes, prefirió alejarse de la Corte y buscar asiento en Valencia, donde permaneció durante algún tiempo al

\footnotetext{
${ }^{34}$ Sobre esta pieza, véanse los comentarios y la edición de Esteva de Llobet, 2009: 156162 y $417-428$.

${ }_{35} \mathrm{Al}$ respecto, véase la edición y certero estudio de López Estrada, 1950-1953.

${ }^{36} \mathrm{La}$ génesis de sus distintos poemarios ha quedado expuesta en Esteva de Llobet, 2009: $127-135$.

${ }^{37}$ La presencia de numerosos espirituales en el entorno de la princesa Juana fue señalada en su día por Bataillon, 1952. A partir de aquella idea, y apoyándonos en los más recientes estudios sobre la Corte en España, hemos incidido sobre la cuestión en Torres Corominas, $2008 b$.

${ }^{38}$ Para conocer las implicaciones doctrinales de la poesía religiosa de Montemayor, véase el trabajo monográfico de Creel, 1981, así como las recientes puntualizaciones de Esteva de Llobet, 2009: 319-347.
} 
amparo de Juan Castellá de Vilanova, a quien, agradecido, dedicó Los siete libros de la Diana poco antes de pasar a Italia, donde encontraría la muerte a comienzos de 1561 .

A la luz de su biografía y de la trayectoria de El Abencerraje, lo más sencillo es pensar que Montemayor, a su regreso de Flandes, tuviera conocimiento de la obra a través de alguna edición temprana de la Crónica que circularía ya, entre 1559 y 1560, por tierras valencianas. En torno a aquellas fechas, por consiguiente, el lusitano habría reelaborado el relato morisco con objeto de interpolarlo en la Diana, que apenas llevaría unos meses disfrutando de la difusión impresa. Aquel fecundo período debió ser, sin embargo, extremadamente difícil y amargo para el portugués, quien, después de lamentar su mala fortuna palaciega, había pasado a formar parte del oscuro y deshonroso universo de lo heterodoxo al verse incluido en el Índice de Valdés. No es extraño, por tanto, que, una vez desplazado — casi literalmente- de una Corte española que abrazaba, como señas de identidad, la intransigencia confesional, la limpieza de sangre ${ }^{39}$ y un obsesivo sentido del honor, Montemayor mirase con simpatía aquella obra donde la virtud de dos caballeros de distinta ley lograba resolver satisfactoriamente un grave conflicto surgido en la frontera - política, religiosa y cultural- de dos mundos en guerra. Entre lo uno y lo diverso, entre la intransigencia y la tolerancia, entre la imposición violenta de la verdad desde el poder político y el respeto a los pareceres y sensibilidades particulares — polos sobre los que se desarrollaba el debate ideológico más importante del momento- gravitaba, pues, no sólo el argumento de El Abencerraje, sino, como en el caso de Jiménez de Embún, la propia existencia de Montemayor, quien, desde las filas de la oposición política —el círculo cortesano portugués, la facción ebolista- no dudó en servirse del relato para echar su cuarto a espadas en la materia.

La biografía de Antonio de Villegas ${ }^{40}$, tercer y último refundidor de la novela según nuestra hipótesis, nos remite, significativamente, al mismo círculo cortesano en que se movió Jorge de Montemayor. De hecho, algunos de los personajes que marcaron la trayectoria palaciega del portugués aparecen de nuevo en los poemas del Inventario - María Manuela de Portugal, doña Juana de Austria ${ }^{41}$ — manifestando inequívocamente cuál era la facción en la que el medinense buscaba cobijo para medrar y acceder quizás algún día al servicio de la Corona. Porque Villegas, frente a Montemayor, no disfrutó jamás de un oficio real, a pesar de dedicar el cancionero a Felipe II y emplear su escudo en la portada. Antes al contrario, pertenecía a una familia venida a

\footnotetext{
${ }^{39}$ Véase al respecto el reciente trabajo de Martínez Millán, 2009.

${ }^{40} \mathrm{La}$ primera biografía documentada de Antonio de Villegas se recoge en Torres Corominas, 2008a: 37-202.

${ }^{41}$ La estrecha colaboración de la princesa con la facción ebolista ha sido puesta de manifiesto por Martínez Millán, 1994a.
} 
menos que, tras contar en generaciones anteriores con el favor de los Habsburgo, había sido progresivamente apartada de los canales de distribución de la gracia, de modo que, a mediados del siglo XVI, tan sólo uno de sus miembros, Antonio de Villegas, primo hermano del escritor, conservaba un modesto oficio de contino por el que recibía 40.000 maravedíes de quitación con cargo a la Hacienda real. El resto de la estirpe, pues, había sido desplazada de palacio por las facciones más intransigentes, cuyo creciente empuje en la Corte de Carlos V había ido condenando al ostracismo - ya muy claramente a partir de 1530 - a todos aquellos servidores que, como en el caso de los Villegas, pertenecían a otras redes clientelares y, en consecuencia, se identificaban con una ideología y una espiritualidad diferentes a las del grupo triunfante ${ }^{42}$. $\mathrm{Si}$ en lo que respecta a Montemayor su propia biografía ilustra con elocuencia el proceso de exclusión al que venimos haciendo referencia, en lo tocante al medinense Antonio de Villegas dicho proceso se percibe mejor si se contempla desde la distancia, en el largo plazo, con el progresivo declive de una familia que, tras ser derrotada y empujada fuera de la Corte, trataba de recuperar posiciones a mitad de la centuria — puestas sus esperanzas en el príncipe Felipe - al amparo de la mentada oposición política, esto es, el círculo cortesano portugués y la facción ebolista.

Para ilustrar este retroceso, basta con remontarse a la generación anterior, cuando los Villegas, firmemente asentados entre la oligarquía mercantil burgalesa ya desde el siglo XV, lograron introducir a varios de sus miembros en la Corte. Fue probablemente en el verano de 1506 - período durante el que Felipe de Habsburgo y Juana de Castilla residieron en la ciudad de Burgoscuando el insigne regidor Alonso de Villanueva ${ }^{43}$, abuelo del escritor, logró infiltrar a su hijo primogénito, Pedro de Villegas, en la Casa de la reina Juana, donde pasó a servir como contino. De este modo, la familia apostaba abiertamente por la vía flamenca ${ }^{44}$, que tan prometedora parecía entonces para los grandes mercaderes castellanos de origen converso - como, muy probablemente, eran los antepasados de Villegas - dada la juventud y el ideario de los nuevos monarcas. Sin embargo, la temprana muerte del rey y el regreso a la Península de Fernando el Católico - y, en consecuencia, del partido aragonés- trastocaron los planes de Pedro de Villegas, quien, a pesar de participar durante la segunda regencia en importantes empresas como la conquista de Navarra (1512), no consiguió durante aquel período progresar en palacio

\footnotetext{
${ }^{42}$ La configuración de un grupo de oposición política en torno al círculo cortesano portugués, fue explicada por Martínez Millán, 1998: 31-38. Allí quedan reseñadas sus profundas divergencias ideológicas y religiosas con respecto a la facción dominante, encabezada por Cobos y Tavera.

${ }^{43}$ Las raíces burgalesas de Antonio de Villegas pueden conocerse a través de Torres Corominas, 2008a: 37-60.

${ }^{44}$ El convulso contexto cortesano de aquellos años ha sido explicado en Martínez Millán, 2000: v. I, 45-72.
} 
ni acceder a oficios de mayor relevancia. La convulsa situación cortesana que se avecinaba con el declinar de Fernando el Católico y la inminente venida a España del príncipe Carlos ${ }^{45}$ debieron desalentar al desafortunado contino, que prefirió abandonar la Corte en 1515 ante la falta de expectativas. Dejando atrás también el solar burgalés, se retiró en tal fecha a Medina del Campo, donde casó con Ana de Buitrago, perteneciente a una familia de mercaderes segovianos. Allí se asentó como cualificado productor de vinos, que después vendía como bien de lujo a través de la ruta del Atlántico, reproduciendo así el modelo mercantil desarrollado por sus antepasados a orillas del Arlanzón. A pesar del éxito de sus negocios, jamás regresaría ni a la Corte ni a Burgos, de cuyo concejo saldría, andados los años, tras vender el regimiento heredado de su padre.

Todavía más significativa resulta la carrera de su hermano Antonio de Villegas ${ }^{46}$, tío del poeta medinense, quien pasó a Flandes en fecha temprana, durante la segunda regencia de Fernando el Católico, donde logró integrarse antes que ningún otro castellano en el servicio de un príncipe Carlos todavía adolescente. Durante aquel período, llegó a ser uno de sus secretarios personales, disfrutando de tal intimidad con el heredero al trono que, en 1517, acompañó a su señor en la galera real durante su viaje de regreso a España. Tras unos primeros años de preeminencia a la sombra del joven Emperador, su estrella se fue apagando paulatinamente - junto con la de otros cortesanos procedentes de la Casa de Borgoña ${ }^{47}$ - ante el imparable ascenso de los antiguos servidores de Fernando el Católico, tales como Francisco de los Cobos, quienes lograron desplazar a los flamencos del entorno de Carlos V coincidiendo con el inicio de las persecuciones contra los partidarios de la vía media y la espiritualidad erasmista ${ }^{48}$. Muerto el secretario Antonio de Villegas en torno a 1535, tan sólo logró que su hijo primogénito, del mismo nombre, fuese beneficiado con un exiguo oficio de contino, mientras que a su segundo vástago, Alonso de Villegas, le fue negada idéntica merced en 1537 a pesar de las alegaciones de su madre, Catalina de Villasante. La situación política, evidentemente, no resultaba propicia para una estirpe que se veía inexorablemente empujada fuera de la Corte ante el triunfo de la facción contraria, que aprovechaba las convulsiones religiosas acaecidas en el Imperio para imponer la intransigencia religiosa en España y, paralelamente, favorecer la carrera de todos aquellos que, integrados en las redes clientelares encabezadas por Cobos y Tavera, comulgaban con aquel ideario.

\footnotetext{
${ }^{45}$ Las disputas faccionales acaecidas en la Corte española durante la segunda regencia de Fernando el Católico han sido reconstruidas en Martínez Millán, 1998: 21-29.

${ }^{46} \mathrm{La}$ trayectoria cortesana del secretario Antonio de Villegas se recoge en Torres Corominas, 2008a: 67 y ss.

47 Véase al respecto, Martínez Millán y Rivero Rodríguez, 2001.

${ }^{48}$ Véase Bataillon, 1966: 432-493.
} 
No es extraño, por tanto, que desde edad temprana el joven Antonio de Villegas, nacido en Medina del Campo en 1522, se sintiese próximo a los sectores de oposición cohesionados en torno al círculo cortesano portugués de la Casa de las Infantas y la propia Casa del Príncipe Felipe - espacios apartados de la primera línea de acción política- donde, entre otros, servía Ruy Gómez de Silva ${ }^{49}$. Como muestra baste recordar los versos elegíacos elaborados por Villegas poco después de la muerte de María Manuela de Portugal (1545), en los que canta las virtudes de la difunta y llora, como Montemayor, la pérdida de la princesa. Pocos años después, a comienzos de 1551, éste y otros poemas, tras haber sido reunidos en una primera colección, serían llevados por el medinense ante las autoridades con intención de obtener privilegio de impresión. Fue entonces cuando el joven escritor sufrió por vez primera los rigores de quienes velaban, desde los órganos centrales de la Monarquía, por la ortodoxia, pues tanto los censores de la Cámara de Castilla como los del Consejo de Inquisición señalaron como inapropiadas, junto a otras composiciones ofensivas, ciertas «obras de devoción», cuyo contenido - obviamente, cercano a la heterodoxia- no conocemos debido a que, en último extremo, no fueron incluidas — quizás por autocensura- en el Inventario $^{50}$.

Durante aquellos años, Villegas permaneció en Medina del Campo, entregado al negocio del vino fundado por su padre. Contempló así, por tanto, desde media distancia, los hechos acaecidos en la Corte vallisoletana durante la convulsa regencia de doña Juana de Austria, personaje que por entonces mereció, como el duque de Sessa, las alabanzas del medinense en unos versos que revelaban su incuestionable filiación ebolista. Precisamente al final de aquel período, en 1558, mientras Fernando de Valdés y Melchor Cano iniciaban su feroz persecución contra los luteranos españoles, tanto los Villegas de Medina como los de Valladolid — hijos del secretario- iniciaron en la Chancillería de aquella ciudad una probanza de hidalguía ad perpetuan rei memoriam, con el fin de que nadie pudiese cuestionar, de ahí en adelante, su nobleza, ni atentar contra los honores y privilegios aparejados a la misma. Unos y otros, por consiguiente, trataban de protegerse tras una ejecutoria - particularmente valiosa durante aquella tempestuosa etapa de transición- de los procesos de exclusión social puestos en marcha por sus enemigos políticos.

Finalmente, más de un lustro después —y tras catorce años de espera-, Antonio de Villegas logró imprimir en su villa natal el variado cancionero donde se compilaba - con significativas variaciones con respecto al corpus de 1551 - la obra de una vida dedicada a la lírica. Para ello, no obstante, hubo

\footnotetext{
${ }^{49}$ La formación y trayectoria política de Ruy Gómez de Silva, príncipe de Éboli, puede conocerse, para sus primeros años, a través de Gonzalo Sánchez-Molero, 1998.

${ }^{50}$ Todas estas circunstancias quedan debidamente reseñadas en Torres Corominas, 2008a: 240-249.
} 
de solicitar un segundo privilegio que, como se recoge en los preliminares del Inventario, fue concedido «a suplicación de Antonio Gómez de Eraso» ${ }^{51}$, esto es, por intermediación del hijo natural del secretario Francisco de Eraso ${ }^{52}$, quien, tras su alianza con Ruy Gómez de Silva, era desde hacía años uno de los patronos más prominentes de la facción ebolista. De manera que, por tercera vez, El Abencerraje encontraba acomodo en una obra surgida en el entorno de quienes, a mediados del siglo XVI, pugnaban en la Corte de Felipe II contra la imposición del centralismo institucional y el confesionalismo religioso.

Y es que la aristocracia fuerista aragonesa — Jiménez de Embún—, los servidores del círculo cortesano portugués - Jorge de Montemayor- y la pequeña nobleza castellana de origen judeoconverso - Antonio de Villegas- tenían sobradas razones para compartir, desde experiencias y problemáticas diversas, una misma actitud beligerante frente al repliegue político, social, religioso y cultural promovido desde 1530 por la Corona - bajo la inspiración de la facción encabezada por Cobos y Tavera - con objeto de preservar, ante el imparable avance de la herejía en el norte de Europa, la paz y estabilidad interna de los reinos hispánicos. Aquel proceso, como es bien sabido, estaba destinado a lograr, empleando diversos mecanismos de control, la homogeneización ideológica y confesional de los súbditos, de manera que no existieran disidencias doctrinales sobre las que cimentar hipotéticas revueltas —como sucediera en el Imperio- que, en última instancia, atentasen contra la soberanía regia. Esto explica que los sectores más intransigentes, tras la lección aprendida en el Continente, fuesen paso a paso ganando terreno en la Corte de Carlos V una vez consumada ya la ruptura con el mundo protestante.

La consecuencia inevitable de su predominio fue la progresiva exclusión de aquellos individuos que, debido a sus orígenes conversos, a su espiritualidad afectiva o a sus planteamientos conciliadores con respecto a la Reforma — estrechado en extremo el espacio para la vía media-, no se identificaban con el ideario triunfante. En ese sentido, las persecuciones dirigidas contra los erasmistas españoles, los alumbrados y, a última hora, los conventículos luteranos descubiertos en Andalucía y Castilla muestran claramente la deriva de aquella corriente de fondo ${ }^{53}$ que, trasladada al ámbito social $-\mathrm{y}$ siempre con la homogeneidad como principio clave - se tradujo en la generalización de los estatutos de limpieza de sangre, destinados a bloquear la integración y progresión de quienes, desde la cuna, estaban estigmatizados —al margen de

${ }^{51}$ Para la biografía de Antonio Gómez de Eraso, véase Martínez Millán, 1998: 367-368.

52 Sobre Francisco de Eraso ha trabajado Carlos Morales, 1994.

${ }^{53} \mathrm{La}$ actividad represora del Santo Oficio en tiempos de Carlos V centró sus esfuerzos en la vigilancia tanto de las desviaciones iluministas (los alumbrados), como de aquellas corrientes espirituales que, como el erasmismo, manifestaban cierta afinidad doctrinal con respecto al universo protestante. Cfr. Martínez Millán, 2007: 80-97. 
sus méritos personales- por ser impuros y pertenecer a una casta maldita. Desde aquel punto de vista, en consecuencia, sólo los descendientes de cristianos viejos, aquellos aguerridos guerreros que habían participado en la Reconquista y profesaban una espiritualidad rigurosamente formalista - constituida, tras siglos de cruzada, en seña de identidad del grupo-, tenían derecho a disfrutar del honor y los privilegios que la nueva sociedad cortesana ofrecía a los súbditos de la Corona ${ }^{54}$.

Homogeneización ideológica y exclusión social fueron, por consiguiente, dos de los ejes fundamentales sobre los que gravitó la política de Carlos V durante sus últimos años de reinado — tal y como demuestra su aceptación del Estatuto de limpieza de sangre aprobado en 1547 por Martínez Silíceo para la catedral de Toledo - señalando el camino por el que, poco tiempo después, transitaría la Monarquía hispana de Felipe II con el fin de preservar su integridad y orden interno. Que, en los distintos contextos de escritura de $E l$ Abencerraje, Jiménez de Embún —en la protección de sus lugares de moriscos_- Jorge de Montemayor — por su proximidad a los autores espiritualeso Antonio de Villegas — debido a sus raíces políticas, sociales y religiosasse viesen salpicados por dicho proceso - los tres, de un modo u otro, padecieron el rigor de la Inquisición- no debe sorprender, por tanto, en absoluto.

A la luz de la historia, en fin, tampoco puede extrañar — ni parecer en modo alguno casual o inocente- que en El Abencerraje valores como la libertad, la ejemplaridad o la tolerancia - manifiestamente contrarios al proceso de confesionalización ${ }^{55}$ - adornen un relato definido en el propio Inventario como «un vivo retrato de virtud, liberalidad, esfuerzo, gentileza y lealtad». Porque la obra presentaba, a través de una novela idealista ambientada en la sugerente frontera ${ }^{56}$ del reino nazarí de Granada ${ }^{57}$, un modelo ideal de comportamiento humano digno de ser imitado por los lectores, a quienes se ofrecía bajo aquel entretenido episodio de sabor caballeresco — conforme a la preceptiva humanística - una provechosa enseñanza, una lección moral fácilmente aplicable a la España de la época. De ahí que, para nuestro propósito,

\footnotetext{
${ }^{54}$ Las señas de identidad cristianoviejas han quedado adecuadamente descritas en Martínez Millán, 2007: 50 y ss.; y 2009: 694 y ss.

${ }^{55} \mathrm{El}$ hecho de que $\mathrm{El}$ Abencerraje fuese concebido, en tanto que texto contradictorio y subversivo, como fruto de una penetrante y dolorosa percepción del momento histórico presente (1560-1565), y no como nostálgica ensoñación de una España pretérita, fue recalcado por Guillén, 1965 (1988): 112-113.

${ }^{56}$ Sobre las particularidades del modo de vida surgido en el espacio fronterizo, véase Ribera Llopis, 1995.

${ }^{57}$ El Abencerraje entronca por esta vía con la tradición humanística italiana, donde autores tan afamados como Boccaccio habían configurado ya, a través de diferentes relatos de ficción, una visión idealizada de Oriente que, en contraste con el clima de intransigencia predominante en la Europa de su tiempo, representaba un espacio propicio para la tolerancia y la generosidad. Así lo explica Stoll, 1995: 433-435.
} 
sea fundamental definir el sistema de valores exaltado en el relato, así como el modo de difusión y expansión del mismo dentro de la ficción.

Sobre la primera cuestión, resulta obligado señalar que la virtud encarnada por Narváez (cuya nobleza depende precisamente de sus atributos morales, no de su linaje) y, más adelante, por el propio Abindarráez — siempre en este orden - recibe su aliento del mundo clásico, concretamente de aquellos pensadores como Cicerón o Séneca que, en sus respectivos tratados de filosofía moral, discurrieron largamente acerca de las cuatro fuentes - Sabiduría, Justicia, Fortaleza y Templanza- de las que procede toda acción virtuosa, esto es, inclinada hacia el bien ${ }^{58}$. Aquellos cuatro principios, en efecto, aparecen perfectamente ilustrados en los diversos motivos de El Abencerraje, hasta el punto de que, en la versión Inventario, las modificaciones textuales de mayor calado parecen orientadas a perfeccionar las simetrías y paralelismos de dicho sistema conceptual ${ }^{59}$. Así, en el texto de Villegas, la Fortaleza de ambos caballeros se manifiesta en la escaramuza; la Justicia, en el cumplimiento de las promesas ${ }^{60}$ (Abindarráez) y en la restitución del virtuoso moro conforme a sus méritos (Narváez), la Templanza, en la renuncia a la mujer amada, bien por respeto al marido ${ }^{61}$ (Narváez), bien por fidelidad a la palabra empeñada (Abindarráez); y la Sabiduría, finalmente, en los diálogos morales (Narváez-escuderos; Narváez-Abindarráez; Abindarráez-Jarifa) y las epístolas, donde quedan expuestas muchas de las enseñanzas extraídas del episodio. En conjunto, pues, todos estos pasajes contribuyen a modelar la figura ideal de los dos protagonistas, cuyo comportamiento remite inequívocamente a una estricta moral neoestoica que, tras haber inspirado gran parte de los códigos caballerescos medievales ${ }^{62}$, constituyó un elemento recurrente para el humanismo y la cultura renacentista ${ }^{63}$.

${ }^{58}$ Sobre el trasfondo senequista de la obra, son fundamentales las aportaciones de López Estrada, 1957: 185-195; y Gimeno Casalduero, 1972.

${ }^{59}$ Nos referimos, en concreto, a las cartas del final (ejemplo de Sabiduría) y al «Cuento de la honra del marido defendida por el amante», que sirve para ilustrar la Templanza de Narváez (su resistencia a las tentaciones del placer) y equipararlo en este punto a Abindarráez.

${ }^{60}$ La promesa en El Abencerraje, además de crear suspense y tensión dramática, condiciona totalmente el comportamiento de los personajes, cuya dimensión moral depende en gran medida de que cumplan o no los compromisos adquiridos. Así lo explica, desde la Pragmática, García (2007).

${ }^{61}$ Véase López Estrada, 1964.

${ }^{62}$ Así lo explica, en su obra clásica, Curtius, 1975: 724-749, quien pondera el influjo ejercido por el De officiis de Cicerón. Hace años, López Estrada, 1965, halló, en el Tesoro de Brunetto Latini (s. XIII) muchos de los rasgos del ideal caballeresco encarnado por Narváez, cuyo sustrato era el pensamiento estoico.

${ }^{63}$ En efecto, el «perfecto cortesano» dibujado por Castiglione - arquetipo en el que se inspiran los personajes de El Abencerraje (López Estrada, 1957: 181-185; Stoll, 1995: 435)— está conformado, en su dimensión moral, por los valores del estoicismo clásico, que inclinan al individuo hacia el bien transitando por esa «austera vía» propuesta por los tratadistas de la Antigüe- 
El camino que esta virtud neoestoica escoge para expandirse en el relato - en lo que podría asemejarse a un proceso de conversión- es la palabra, el ejemplo personal, el convencimiento y la amistad, jamás la imposición violenta ${ }^{64}$, siguiendo un modo de relación humana ponderado ya en las obras de los principales autores estoicos ${ }^{65}$. En ese sentido, Rodrigo de Narváez — haciendo uso de su autoridad moral- ejerce de guía para los demás personajes, que reciben su magisterio a través de diálogos y epístolas, y encuentran en su excelsa figura un modelo digno de ser imitado. Y es que su causa, más allá de sus deberes como bellator, es la defensa de la honestidad ${ }^{66}$, de una virtud que brilla con luz propia engastada en el corazón del hombre que la acoge, sea éste musulmán o cristiano. Porque la verdadera victoria — siguiendo el código propuesto en la ficción- consiste, al margen de las conquistas militares, en ganar la voluntad ajena, no en someterla, tal y como el mismo Abindarráez lo expresa al final de la escaramuza: «Matarme bien podrás - dijo el moro- que en tu poder me tienes, mas no podrá vencerme sino quien una vez me venció» ${ }^{67}$. El triunfo del cristiano, por tanto, no puede alcanzarse a través de las armas, sino de la clemencia para con el vencido, quien, tras su liberación, quedará prendado del alcaide de Álora con unos lazos tan estrechos — «Las buenas obras prisiones son de los nobles corazones», dirá el moro en una de las cartas finales - que ni su amada Jarifa acertará a deshacerlos ${ }^{68}$. Así, por esta misma vía, los demás personajes sucumben, uno tras otro, al imperio de la virtud, bien por influjo directo del alcaide de Álora, bien por iniciativa de quienes adoptan su credo: Jarifa tras la predicación de Abindarráez en el lecho nupcial (tras ser rechazada su alternativa, decide marchar a la prisión con su marido), el rey de Granada, secundando la recta intención del capitán cristiano (restituye a Abindarráez en la sociedad granadina); y el

dad. Sobre el particular, son esenciales los trabajos de Quondam, 1980, 1987 y 2006, entre otros. A partir de sus enseñanzas, hemos reconstruido los rasgos de aquel modelo una vez incorporado, con la traducción de Boscán, a la tradición española en Torres Corominas, 2010.

${ }^{64}$ Este proceso fue explicado por Guillén, 1965 (1988): 150 y ss.

${ }^{65}$ Ya en su día, López Estrada, 1957: 188, trajo oportunamente a colación una cita de Séneca tomada de las Epístolas morales a Lucilio, LXIV, donde se señalaba que la virtud es admirable, y que de tal admiración nace el deseo de seguirla. Igualmente acertadas resultan las observaciones de Avilés, 2003, quien recuerda cómo, en el tratado ciceroniano De amicitia, el ejercicio de la virtud $-\mathrm{y}$ el consecuente renombre y buena fama de quien la ejerce - constituyen un excelente modo de granjearse la amistad ajena.

${ }^{66}$ Véanse las observaciones de López Estrada en El Abencerraje, 1993: 53 y ss.

${ }^{67}$ Sobre el empleo del lenguaje militar para articular los diversos temas de la obra, véase Holzinger, 1978.

${ }^{68}$ Sobre la oposición entre las obligaciones sociales impuestas por la palabra dada a Narváez y el deseo amoroso representado por Jarifa, ha ofrecido una nueva perspectiva Bass, 2000. En la misma línea de los estudios de género, Hernández-Pecoraro, 2002, pondera la existencia de un punto de vista alternativo —encarnado por Jarifa — al sistema de valores representado por Narváez. 
padre de Jarifa, finalmente, asumiendo la honesta decisión de su hija (perdona a los jóvenes moros por haberse casado sin su consentimiento y reconoce el acierto de tal elección).

Al calor de los procesos anteriormente descritos, por tanto, el episodio recreado en El Abencerraje cobra pleno sentido histórico, pues aborda subrepticiamente, bajo la apariencia de un amable relato idealista, el problema más acuciante del momento, esto es, la cuestión de la diversidad. Y lo hace equiparando las virtudes del caballero moro y el cristiano - como individuos capaces de alcanzar semejante perfección ${ }^{69}$ - , poniendo de manifiesto que la paz y la armonía no precisan de la homogeneidad religiosa y cultural, ni requieren la represión forzosa del vencido, sino el hermanamiento de los hombres bajo una excelsa moral de origen clásico y alcance universal ${ }^{70}$. No obstante, en este verdadero sueño del humanismo, la posición del cristiano, encarnada por Rodrigo de Narváez, es siempre dominante, propia del vencedor, circunstancia que lo habilita - como a la triunfante Monarquía hispana de Felipe IIpara establecer las reglas de juego, las normas que habrán de definir su relación con el derrotado, con el diferente. Esta manifiesta desigualdad marca los límites semánticos de la obra, toda vez que la asunción de los valores encarnados por Narváez al otro lado de la frontera - la ponderación de un pensamiento alternativo (genuinamente $m u s u l m a ́ n^{71}$ ) habría sido inconcebible para un autor católico de la época - no supone sino la asimilación del contrario - la moral neoestoica es, en el marco de la ficción, una moral cristiana - por muy benignos y excelsos que parezcan sus fines y sus métodos desde la perspectiva occidental. Inmersos, por consiguiente, en este proceso civilizador, en la construcción de un nuevo orden conforme a los designios del vencedor, la significación histórica de El Abencerraje se concentra - acotado su alcanceen el modo de llevar a cabo esta empresa una vez asegurado, como en la España de 1560, el control sobre el otro $^{72}$.

${ }^{69}$ Diversos autores medievales, como Diego de Valera o Gutierre Díez de Games, consideraban que, debido a su nobleza, los caballeros musulmanes - al igual que los conversos- estaban tan capacitados como los cristianos para ganar honra y fama a través del ejercicio de la virtud. Cfr. López Estrada, 1957: 287-291.

${ }^{70} \mathrm{El}$ alcance universal de la virtud, capaz de iluminar y hermanar las almas de los hombres, fue proclamado en el De beneficiis de Séneca (cfr. López Estrada, 1957: 192-193). El mismo autor, 195-197, considera que la caridad cristiana - principio de todas las virtudes caballerescas - subyace, como telón de fondo, bajo el perdón y la hospitalidad de Narváez, a pesar de que, como él mismo reconoce en El Abencerraje, 1993: 55, la lección moral de la obra es de naturaleza profana y responde a un espíritu civil.

${ }^{71} \mathrm{Ni}$ en la experiencia sentimental, ni en la asunción del destino (manejan la idea de Fortuna al modo de los paganos), ni en los valores atribuidos al caballero, ni en la organización patriarcal de la sociedad, ni en la concepción política del reino y ni siquiera en lo religioso (aspecto apenas abordado en la obra), los musulmanes de El Abencerraje proyectan una visión del mundo o encarnan un modo de vida alternativos al universo cristiano. Antes al contrario, los moros reciben todos sus elementos constitutivos de la tradición occidental.

${ }^{72}$ Véanse las observaciones de Burshatin, 1984. 
Por ese camino, el sentido de la novela entronca con las corrientes de pensamiento que, desde tiempos de los Reyes Católicos, abogaron — sin dudar de la supremacía cristiana- por una asimilación pacífica y progresiva de la comunidad morisca española, una vez concluida la Reconquista con la toma de Granada (1492). Si en aquel primer momento fueron los cortesanos afines a Isabel la Católica —encabezados por Hernando de Talavera- quienes llevaron a cabo aquella empresa recurriendo al ejemplo personal y a la predicación para atraer a los musulmanes hacia la fe católica —a través de unos métodos, por tanto, que aunaban lo útil y lo honesto-, en torno a 1560 hubieron de ser los ebolistas quienes, en la Corte del Rey Prudente, defendieran - frente a los grupos de poder que deseaban el empleo de métodos más expeditivos - el mantenimiento de políticas transigentes (jalonadas de concordias y acuerdos negociados) no sólo con respecto a la minoría morisca, sino también en lo concerniente a la heterodoxia religiosa y a la integración de los judeoconversos españoles.

Que el servidor de Jiménez de Embún, Jorge de Montemayor o Antonio de Villegas — todos ellos encuadrados dentro de la oposición política ${ }^{73}$ - fuesen quienes reelaborasen el relato y lo hiciesen circular por los reinos hispánicos durante un período tan decisivo para el futuro de quienes no compartían los valores del grupo dominante resulta, por consiguiente, revelador acerca del sentido profundo de la obra. En efecto, El Abencerraje, dibujando un cuadro idealizado que funcionaba meramente por contraste con respecto a la realidad de su tiempo ${ }^{74}$, se dirigió frontalmente — a cobijo de la Inquisicióncontra la máxima fundamental que había inspirado desde hacía décadas la acción política de los sectores más intransigentes, esto es, la convicción de que sólo mediante la fuerza, la represión y la intolerancia podría lograrse la homogeneización de los súbditos y, con ella, la paz del Imperio Habsburgo. $\mathrm{Su}$ propuesta, en cambio, nítidamente expresada en el curso de la novela - como un hermoso alegato del humanismo a las puertas de su ocaso- trataba de conquistar por la vía del bien antes descrita el corazón del otro al considerar inalienable la libertad del individuo tanto para acoger la fe católica como para adoptar las señas de identidad o el sistema de valores predominante en el seno de la comunidad política.

Este canto a la tolerancia, a las posibilidades de integración y convivencia entre diferentes, no manejaba, en consecuencia, otro código que el del humanismo clásico, reformulado a mediados del siglo XVI en un relato idea-

${ }^{73}$ El hecho de que El Abencerraje se debiera a la labor de algún individuo perteneciente o próximo a los sectores de oposición ha constituido una idea recurrente para la crítica que, en todo caso, ha manejado fundamentalmente la historia social como marco teórico (cfr. Guillén, 1971; Shipley, 1978; Carrasco Urgoiti, 1983; Rey Hazas y Sevilla Arroyo, 1987; El Abencerraje, 1993: 59-62; Armistead, 1995; o Stoll, 1995: 440 y ss.).

${ }^{74}$ Esta estrategia enunciativa fue ya descrita por Guillén, 1965 (1988): 116-117; y Holzinger, 1978: 233-237. 
lista (pero verosímil) que, a caballo entre la historia y el universo caballeresco, adquiriría con el tiempo carácter fundacional. Si las viejas ideas fueron vertidas en odres nuevos conforme la prosa de ficción exploraba - a partir del diálogo, la epístola o la novella - los caminos que desembocarían en la novela moderna - unos caminos por los que fluyó en ocasiones el pensamiento crítico a resguardo de la censura-, no es menos cierto que, desde un punto de vista faccional, puede trazarse una trayectoria paralela a la anterior siguiendo el curso de quienes, en la Corte, defendieron los principios del humanismo político. Dicha línea arranca en torno a los cortesanos afines a Isabel la Católica, prosigue con los partidarios de Felipe el Hermoso, renace con la venida a España de los servidores flamencos de Carlos V y, finalmente, culmina, a partir de la década de 1530 , en el círculo cortesano portugués — donde se refugió la oposición política- y la red clientelar encabezada, ya mediada la centuria, por el príncipe de Éboli, Francisco de Eraso y la princesa doña Juana. Entre aquellos hombres — que tan vinculados se hallaban al origen y trayectoria personal de Montemayor y Villegas-, circuló, generación tras generación, con las variaciones propias de cada período, una ideología que, en líneas generales, manifestaba una actitud más tolerante e integradora con respecto a los distintos grupos humanos que, como los moros del reino de Granada o los indios americanos, fueron cayendo paulatinamente bajo la dominación del Imperio Habsburgo. Resulta absolutamente coherente, por tanto, que El Abencerraje, pertrechado con aquellas ideas, surgiese - a la sombra de Jiménez de Embún, en primer término, y después auspiciado por dos reconocidos ebolistas como Montemayor y Villegas- en el entorno de quienes por entonces perdían su última batalla política frente al confesionalismo católico.

En efecto, si tras la reagrupación de la Corte en 1559 con el regreso a España de Felipe II los ebolistas lograron, después de tres décadas en la oposición, hacerse con el control de la Monarquía — con la desaparición de sus mayores enemigos, Fernando de Valdés y Melchor Cano-, muy pronto el fracaso de su política de catequización y conversión pacífica de los protestantes en Flandes y de los moriscos en Granada obligó a la Monarquía a tomar un nuevo rumbo con el fin de controlar férreamente aquellos territorios ${ }^{75}$. Para ello se apoyó, a partir de 1565, en hombres como el cardenal Diego de Espinosa - quien encabezaba un disciplinado grupo de letrados a su servicio- o en el mismo duque de Alba, que recuperó su preeminencia después de pasar varios años en el ostracismo. Así, la llegada de Pedro de Deza a la Chancillería de Granada (1566) y la partida de Fernando Álvarez de Toledo hacia Flandes (1567) señalaron el rumbo de los nuevos tiempos. Ambos emplearon la fuerza para someter, respectivamente, a las minorías protestante y moris-

${ }^{75}$ La situación de la Corte durante aquel período ha sido descrita por Martínez Millán, 1998: 81-98. 
ca, desencadenando en poco tiempo las rebeliones y conflictos internos que, con su actuación, trataban de prevenir; de manera que, a la postre, su política representó un verdadero desastre para la Corona ${ }^{76}$.

A partir de aquellos años, el enfrentamiento abierto entre la Europa protestante y un catolicismo en armas que gravitaba entre las Cortes de Madrid y Roma, modificó profundamente la cultura hispánica, que, sometida a la estrecha vigilancia de la censura, reorientó el clasicismo hacia actitudes más persuasivas - las artes y las letras al servicio de una verdad católica- que revolucionarias, al modo de los studia humanitatis en las postrimerías de la Edad Media. En ese contexto, El Abencerraje constituyó una de las últimas y más puras manifestaciones del humanismo español, cuya exaltación de la virtud, la libertad y la tolerancia se erigió en testimonio de una visión del mundo que, tras representar una alternativa posible a comienzos del reinado de Carlos V y buscar después refugio entre las filas de la oposición, quedaría eclipsada por largo tiempo ante el avance de la intransigencia religiosa y el repliegue social y cultural de la Monarquía de Felipe II $^{77}$. Desde entonces, aquella corriente ideológica — de la que formaron parte, desde su particular experiencia personal, los tres autores de la novela- habría de buscar, para no caer en el silencio o sufrir el acoso de los centinelas de la fe, nuevos y más sutiles cauces de expresión — tal y como ejemplifica la obra de Cervantescapaces de encarnar y mantener con vida — subrepticia, velada, metafóricamente- unos valores que, en los albores del confesionalismo filipino, no encontraron mejor acomodo que un hermoso relato de frontera.

\section{BIBLIOGRAFÍA CITADA}

Álvarez-Ossorio Alvariño, Antonio (1998). «Corte y cortesanos en la Monarquía de España», en G. Patrizi y A. Quondam (eds.), Educare il corpo, educare la parola nella trattatistica del Rinascimento. Roma: Bulzoni, pp. 297-365.

Armistead, Samuel G. (1995). «El Abencerraje as a converso text», en C. I. Nepaulsingh (ed.), Apples of Gold in Filigrees of Silver. Jewish Writing in the Eyes of Spanish Inquisition. New York-London: Holmes \& Meier, pp. 82-101.

Avilés, Luis F. (2003). «Los suspiros del Abencerraje», Hispanic Review. LXXI, pp. 464-465.

Bass, Laura R. (2000). «Homosocial Bonds and Desire in the Abencerraje», Revista Canadiense de Estudios Hispánicos. XXIV, pp. 453-472.

Bataillon, Marcel (1952). «Jeanne D’Autriche, Princess de Portugal», en Études sur le Portugal au temps de l'Humanisme. Coimbra, pp. 257-283.

Bataillon, Marcel (1964). «Salmacis y Trocho en el Abencerraje», en Varia lección de clásicos españoles. Madrid: Gredos, pp. 27-38.

Bataillon, Marcel (1966). Erasmo y España, A. Alatorre (trad.). (2 ed. corregida y aumentada). Madrid: Fondo de Cultura Económica.

\footnotetext{
${ }^{76}$ El proceso de confesionalización filipino ha sido estudiado por Martínez Millán, 1994b y 1998: 103-126.

${ }^{77}$ Véase Martínez Millán, 2001.
} 
Burshatin, Israel (1984). «Power, Discourse and Metaphor in Abencerraje», Modern Language Notes. IC, pp. 195-213.

Carrasco Urgoiti, $\mathrm{M}^{\mathrm{a}}$. Soledad (1968). «El relato Historia del moro y Narváez y El abencerraje», Revista Hispánica Moderna. XXXIV, pp. 242-255.

Carrasco Urgoiti, $\mathrm{M}^{\circ}$. Soledad (1969). El problema morisco en Aragón al comienzo del reinado de Felipe II. Chapel Hill: Department of Romance Languages, University of North Carolina.

Carrasco Urgoiti, M. Soledad (1972). «Las cortes señoriales del Aragón mudéjar y El Abencerraje», en Homenaje al profesor Casalduero. Madrid: Gredos, pp. 115-128.

Carrasco Urgoiti, $\mathrm{M}^{\mathrm{a}}$ Soledad (1983). «El trasfondo social de la novela morisca del siglo XVI», Dicenda. II, pp. 43-56.

Carrasco Urgoiti, M ${ }^{a}$ Soledad (con F. López Estrada y F. Carrasco) (2001). La novela española en el siglo XVI. Madrid: Iberoamericana.

Carlos Morales, Carlos Javier de (1994). «El poder de los secretarios reales: Francisco de Eraso», en J. Martínez Millán (ed.), La corte de Felipe II. Madrid: Alianza Editorial, pp. 107-148.

Curtius, Ernst R. (1975). Literatura europea y Edad Media latina. México: Fondo de Cultura Económica.

El Abencerraje. Novela y romancero (1993), F. López Estrada (ed.). Madrid: Cátedra.

Esteva de Llobet, $\mathrm{M}^{\mathrm{a}}$. Dolores (2009). Jorge de Montemayor: Vida y obra de un advenedizo portugués en la corte castellana. Barcelona: PPU.

Ezquerra Revilla, Ignacio (2000). «Las casas de las infantas doña María y doña Juana», en J. Martínez Millán (dir.), La corte de Carlos V. Madrid: Sociedad Estatal para la Conmemoración de los Centenarios de Felipe II y Carlos V. Vol. I, tomo II, pp. 125-152.

Fosalba Vela, Eugenia (1990). El Abencerraje pastoril. Barcelona: Universidad Autónoma de Barcelona, Dpto. de Filología Española.

Fosalba Vela, Eugenia (1994). La Diana en Europa: ediciones, traducciones e influencias. Barcelona: Seminari de Filología i d'Informática. Department de Filologia Espanyola. Universitat Autónoma.

García, Dulce María (2007). «Las funciones de la promesa en El Abencerraje», Revista de Filología Española. LXXXVII, pp. 45-78.

Gimeno Casalduero, Joaquín (1972). «El Abencerraje y la hermosa Jarifa: composición y significado», Nueva Revista de Filología Hispánica. XXI, pp.1-22.

Gonzalo Sánchez-Molero, José Luis (1998). «La formación de un privado: Ruy Gómez de Silva en la Corte de Castilla (1526-1554)», en J. Martínez Millán (dir.), Felipe II (15271558): Europa y la Monarquía Católica. Madrid: Parteluz. Vol. I, tomo I, pp. 379-400.

Guillén, Claudio (1965). «Individuo y ejemplaridad en el Abencerraje», en El primer Siglo de Oro. Estudios sobre géneros y modelos (1988). Barcelona: Crítica, pp.109-153.

Guillén, Claudio (1971). «Literature as Historical Contradiction: El Abencerraje, the Moorish Novel and the Ecologue», en Literature as System: Essays Toward the Theory of Literary History. Princetown: Princetown University Press, pp. 159-217.

Hernández-Pecoraro, Rosilie (2002). «Jarifa's Choice: A Gendered Reading of «El Abencerraje y la hermosa Jarifa»», Bulletin of Spanish Studies. LXXIX, pp. 429-446.

Holzinger, Walter (1978). «The Militia of Love, War and Virtue in the Abencerraje y la hermosa Jarifa: a Structural and Sociological Reassessmente», Revista Canadiense de Estudios Hispánicos. II, pp. 227-238.

López Estrada, Francisco (1950-1953). «La epístola de Jorge de Montemayor a Diego Ramírez Pagán. Una interpretación del desprecio por el Cortesano en la Diana», en Estudios dedicados a Menéndez Pidal. Madrid: S. Aguirre. Vol. IV, pp. 387-406.

López Estrada, Francisco (1957). El Abencerraje y la hermosa Jarifa: Cuatro textos y su estudio. Madrid: Publicaciones de la Revista de Archivos, Bibliotecas y Museos. 
López Estrada, Francisco (1959). «El Abencerraje de Toledo, 1561», Anales de la Universidad Hispalense. XIX, pp. 1-60.

López Estrada, Francisco (1964). «Sobre el cuento de la honra del marido defendida por el amante, atribuido a Rodrigo de Narváez», Revista de Filología Española. XLVII, pp. 331-339.

López Estrada, Francisco (1965). «Tres notas al Abencerraje», Revista Hispánica Moderna. XXXI, pp. 265-273.

Lucía Megías, José Manuel (2000). Imprenta y libros de caballerías. Madrid: Ollero \& Ramos.

Martínez Millán, José (1992). «Grupos de poder en la corte durante el reinado de Felipe II: la facción ebolista, 1554-1573», en Instituciones y elites de poder en la monarquía hispana durante el siglo XVI. Madrid: Universidad Autónoma, pp. 137-197.

Martínez Millán, José $(1994 a)$. «Familia Real y grupos políticos: La princesa Doña Juana de Austria (1535-1573)», en La corte de Felipe II. Madrid: Alianza Editorial, pp. 73-106.

Martínez Millán, José (1994b). «En busca de la ortodoxia: el Inquisidor General Diego de Espinosa», en La corte de Felipe II. Madrid: Alianza Editorial, pp. 189-227.

Martínez Millán, José (1998). Felipe II (1527-1598). La configuración de la monarquía hispana. Salamanca: Junta de Castilla y León.

Martínez Millán, José (dir.) (2000). La corte de Carlos V. Madrid: Sociedad Estatal para la Conmemoración de los Centenarios de Felipe II y Carlos V. 5 vols.

Martínez Millán, José (2001). «Del humanismo carolino al proceso de confesionalización filipino», en J. L. García Hourcade y J. M. Moreno Yuste (coors.), Andrés Laguna: humanismo, ciencia y política en la Europa renacentista. Actas del Congreso Internacional. Valladolid: Junta de Castilla y León, pp. 123-159.

Martínez Millán, José y Rivero Rodríguez, Manuel (2001). «La coronación imperial de Bolonia y el final de la «vía flamenca» (1526-1530)», en J. Martínez Millán (coord.), Carlos $V$ y la quiebra del humanismo político en Europa (1530-1558). Madrid: Sociedad Estatal para la Conmemoración de los Centenarios de Felipe II y Carlos V. Vol. I, pp. 131-150.

Martínez Millán, José (2003). «Elites de poder en las Cortes de las Monarquías española y portuguesa en el siglo XVI: los servidores de Juana de Austria», Miscelánea Comillas. LXI, pp. 169-202.

Martínez Millán, José (2007). La Inquisición Española. Madrid: Alianza Editorial.

Martínez Millán, José (2009). «Nobleza hispana, nobleza cristiana: los estatutos de limpieza de sangre», en M. Rivero Rodríguez (coor.), Nobleza hispana, nobleza cristiana. La Orden de San Juan. Madrid: Ediciones Polifemo, pp. 677-757.

Merimée, Henri (1928). «El Abencerraje d'après diverses versions publiées au XVI ${ }^{\circ}$ siècle», Bulletin Hispanique. XXX, pp. 160-163.

Moll, Jaime (2008). «Sobre la historia de la primera edición de «Las obras» de Jorge de Montemayor», Voz y Letra. XIX, 2, pp. 3-8.

Montemayor, Jorge de (1998). Diálogo espiritual, Ma . Dolores Esteva de Llobet (ed.). Kassel: Reichenberger.

Montemayor, Jorge de (2006). Segundo Cancionero espiritual. Amberes, 1558, Mª. Dolores Esteva de Llobet (ed.). Berlín: Reichenberger.

Montero Delgado, Juan (2004). «Sobre imprenta y poesía a mediados del XVI (con nuevos datos sobre la princeps de las obras de Jorge de Montemayor)», Bulletin Hispanique. CVI, pp. 81-102.

Navarro Gómez, José (1978). «El autor de la versión de El Abencerraje contenida en la Diana, ¿era Montemayor?», Revista de Literatura. XXXIX, pp.101-104.

Quondam, Amedeo (1980). «La forma del vivere. Schede per l'analisi del discorso cotigiano», en A. Prosperi (ed.), La corte e il «Cortegiano». Vol. II, Un modello europeo. Roma: Bulzoni, pp. 15-68. 
Quondam, Amedeo (1987). «Introduzione», en Baldassar Castiglione, Il libro del Cortegiano. Milán: Garzanti, pp. VII-LI.

Quondam, Amedeo (2006). «»Formare con parole». L'institutio del moderno gentiluomo», History of Education and Children's Literature. I, pp. 23-54.

Rey Hazas, Antonio; y Sevilla Arroyo, Florencio (1987). «Contexto y punto de vista en el Abencerraje», Dicenda. VI, pp. 419-428.

Ribera Llopis, Juan M. «La narrativa breve en las literaturas peninsulares: Història de Jacob Xalabín y El abencerraje y la hermosa Jarifa», en J. Paredes (ed.), Medioevo y literatura. Actas del V Congreso de la Asociación Hispánica de Literatura Medieval. Granada: Universidad. Vol. IV, pp. 123-136.

Rodríguez Salgado, $\mathrm{M}^{\mathrm{a}}$. José (1992). Un Imperio en transición. Carlos V, Felipe II y su mundo. Barcelona: Crítica.

Ruiz Cabello, Francisco Miguel (2000). «Sobre Jorge de Montemayor, poeta y cantor en la corte española», Philologia Hispalenses. XIV, 1, pp. 127-142.

Shipley, George A. (1978). «La obra literaria como monumento histórico: el caso del Abencerraje», Journal of Hispanic Philology. II, pp. 103-120.

Stoll, André (1995). «Avatares de un cuento del Renacimiento. El Abencerraje, releído a la luz de su contexto literario cultural y discursivo». Sharq Al-Andalus: Estudios mudejares y moriscos. XII, pp. 429-460.

Torres Corominas, Eduardo (2005). «1551: el primer «inventario» de Villegas», Edad de Oro. XXIV, pp. 407-433.

Torres Corominas, Eduardo (2008a). Literatura y facciones cortesanas en la España del siglo XVI. Estudio y edición del Inventario de Antonio de Villegas. Madrid: Ediciones Polifemo.

Torres Corominas, Eduardo (2008b). «La corte literaria de doña Juana de Austria (15541559)», en J. Martínez Millán y $\mathrm{M}^{a}$. P. Marçal Lourenço (coors.), Las relaciones discretas entre las Monarquías hispana y portuguesa. Las Casas de las reinas. Madrid: Ediciones Polifemo. Vol. II, pp. 919-971.

Torres Corominas, Eduardo (2010). «El Cortesano de Castiglione: Modelo antropológico y contexto de recepción en la corte de Carlos V», en J. Martínez Millán y M. Rivero Rodríguez (coors.), Centros de poder italianos en la Monarquía hispánica (siglos XVXVIII). Madrid: Ediciones Polifemo. Vol. II, pp. 1183-1234.

Torres Corominas, Eduardo (2012). «Jorge de Montemayor: un heterodoxo al servicio de la Monarquía hispana», en J. Martínez Millán y M. Rivero Rodríguez (coors.), La Corte en Europa. Política y Religión (siglos XVI-XVIII). Madrid: Ediciones Polifemo. Vol. II, pp. 1329-1373.

Villegas, Antonio de (1955-1956). Inventario, F. López Estrada (ed.). Madrid: Joyas bibliográficas.

Whinnom, Keith (1959). «The Relationship of the three texts of El Abencerraje», The Modern Languaje Rewiew. LIV, pp. 507-517.

Fecha de recepción: 16 de junio de 2010

Fecha de aceptación: 31 de enero de 2011 